\title{
Authenticity of Ficus Hispida as a Local Traditional Product in the Lembah Lenggong World Heritage Site
}

\author{
Siti Hajar Abd Aziz ${ }^{1}$, Zuraini Zakaria ${ }^{2}$, Ziyad Rafiqi Mohammad ${ }^{3}$ \\ ${ }^{1,2,3}$ Biology Program, School of Distance Education, Universiti Sains Malaysia, 11800, Penang, \\ Malaysia
}

\begin{abstract}
Lembah Lenggong is a place well known amongst locals as an archaeological site; the valley has been attested as a World Heritage Site. There is an overwhelming variety of plant species that are uniquely used in their cultural and traditional cuisines including Ficus hispida (Senia). Ficus hispida is a well-known species restricted to the native people in Lembah Lenggong. It is recognized as one of the plants used specifically in the traditional cuisine of the locals, especially amongst the old folks. The plant leaves are a major part of a local traditional dish called 'Masak Pindang'. The fruit of Ficus hispida is also edible, and consumed locally in candied form (halwa). In their traditional herbal remedies, Ficus hispida is used in treating wounds and as a medicine in post and pre natal care (maternal remedies). The desired outcome of this study is to emphasize and promote this specific species as one of the more unique products of Lembah Lenggong in a tourism aspect. The traditional knowledge and practices involving the use of Ficus hispida should be cherished and treasured by future generations to retain the authenticity of their local traditional and cultural products in the light of the awakening tourism industry.
\end{abstract}

\section{Introduction}

The definition of traditional food varies according to the locality and the individual's perception towards food. Tradition means beliefs and practices rehearsed from one generation to the next, electing their origin and ascertaining the identity of their culture [1]; whereas food is described as an edible resource harvested from natural products consumed for daily dietary needs. Thus, traditional food conveys both the need and the culture of vastly disparate regions, religions, races, levels of availability of natural resources and eating habits of a particular community.

Authenticity is a term used to portray the novelty of a certain cultural product, whereby defining the authentic is a convoluted effort. Traditional food is considered one native product determining the authenticity of one's culture. It is measured in terms of ways of preparing and ingredients used. Therefore, traditional food needs to be valued based on its novelty and eccentricity [2].

Generally, traditional food comprises a product of culture and is classified as an element of cultural tourism. Cultural tourism is a fraction of tourism concerned with the way of life, beliefs, practices, history and other elements that help in building the identity of a particular society [3]. The value of cultural tourism is based on the purpose of rehabilitation, preservation, expression, experience, not as a discretionary activity for hedonistic or economic benefits, but in order to protect authentic heritage to be accessed by future generations. It plays a vital role to market the cultural products of a particular society through an exchange experience between peoples. It helps to provide 
a continuous impetus to resuscitate lost tradition, culture, art and traditional practices in a society.

Traditional food is thus seen as a cultural asset, asserted to be an ecotourism product accompanied by both tangible and intangible benefits [4]. Basically traditional food developed by a society, emanates from the rural areas which gives the unique value to their local's cultural identity. Their eating habits specifically evolved from the initial survival needs of a particular community. The variety of ingredients used in traditional cuisine originated from the available natural resources surrounding their homeland.

Interestingly, the combination of culture and tourism increases the attractiveness and competitiveness in promoting a region as an excellent destination. The richness of cultural elements present in the society creates the distinctiveness of the products in a global market atmosphere [5]. It is an array of examples in tourism that promotes a region based on their cultural products [6]. The development of cultural tourism is basically fostered by the world demand in tourism industries which can be related to an increase and an individual interest in culture, experience, accessibility, attractiveness, impact in economy and rehabilitation satisfaction [7]. Cultural tourism gives many benefits to the society it focuses on, especially to the local community in a rural region [8].

According to Smith [9], cultural tourism is a crucial measurement for conservation and preservation of heritage products in a long run. Likewise, heritage culture is viewed as a prominent element in the image building processes of a society. The expressions of heritage cultural products can be classified into tangible and intangible feature categories; tangible assets are commonly presented in the forms of monuments, historical buildings, traditional apparel, cuisine and other manifold objects, whereas intangible assets are most likely found in the form of practices and beliefs inherited from forefathers. These two types of cultural products give a synergetic impact on a destination's attractiveness in a region [10].

Conclusively, the role of ecotourism provides a debated platform from various aspects which include the conservation of natural and cultural products, besides primarily the socio-development [11]. This study is noteworthy as it reveals a new dimension of cultural tourism in the form of a natural resource significant as a traditional food supplement to the community in Lembah Lenggong, Perak.

\section{Methodology}

Lembah Lenggong is located in Hulu Perak district, about $50 \mathrm{~km}$ north of Kuala Kangsar, the royal town of Perak. A place well known amongst locals as an archaeological site, Lembah Lenggong has been declared a World Heritage Site on 30th June 2012 by UNESCO, a worldwide organization for educational, scientific and culture. It is surrounded by two mountain ranges, namely Banjaran Titiwangsa and Banjaran Bintang Hijau. Lembah Lenggong encompasses 3 sub-districts known as Durian Pipit, Temelong and Lenggong. Richness on the local's traditional culture and natural resources makes the valley more attractive.

Interviews were conducted with the local people from all walks of life in all of the villages in the sub-districts. A guided field study was also conducted whereby plant species related to the communities' traditional food habits were collected for observation, and to be identified by plant taxonomists from the Eco-Hub, Universiti Sains Malaysia in Penang. Local names of particular endemic species as well as descriptions of their uses were obtained through the interviews of particularly knowledgeable respondents like the village head, older more experienced villagers and traditional medicine practitioners. It seems that the knowledge behind preparing traditional food applied in their daily life is acquired from their forefathers and is basically based on folklore.

\section{Results and Discussion}

The coordinated individual and group interviews have resulted in an inventory data of as many as fifty plant species used by the local people in their traditional food preparation. Amongst the recorded plant species, one particular native species is specifically used in the local traditional dish 
called 'Masak Pindang' (Figure 1).

The plant species is Ficus hispida, locally called 'Senia'. Using Senia leaf shoots in food preparation is considered one of the eccentricities in Lembah Lenggong's community. Although the practice is considered customarily to the community, it is vice versa to outsiders whereby this idea appears interesting and has the prospect of being a tourist attraction.

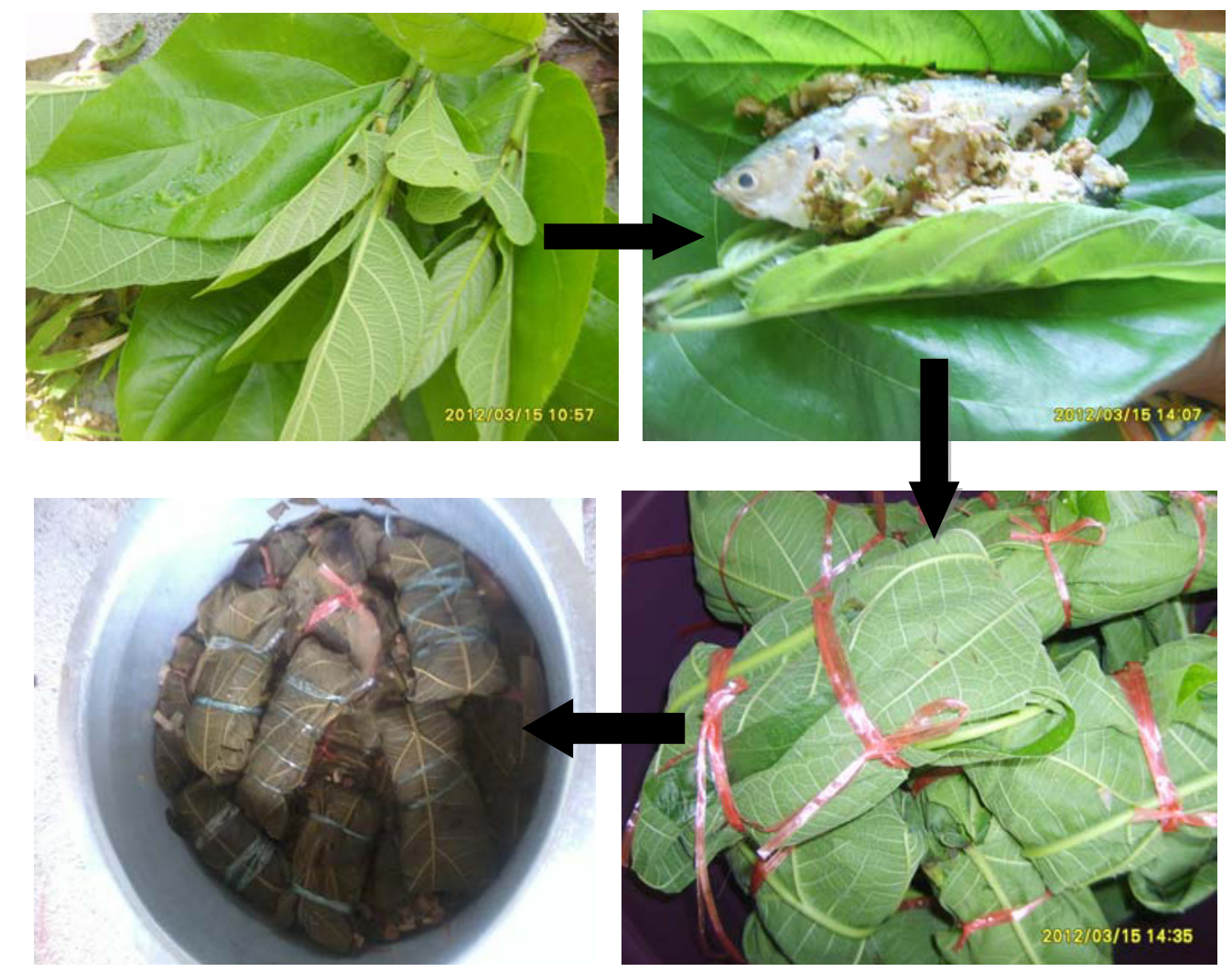

Figure 1. Process of 'Masak Pindang'

The preparation of 'Masak Pindang' begins with the washing of the hairy leaves of Ficus hispida followed by drying using a cloth. The leaves are then used to wrap the freshwater fish before decocting. The duration for the decoction process is about 8 hours long to extract the flavor of both leaves and fish. The freshwater fish is stuffed with several types of spice including coriander (Persicaria odorata), Languas galanga (Alpinia galanga), onion (Allium cepa), tamarind (Garcinia atroviridis), bilimbi (Averrhoa bilimbi), chilli pepper (Capsicum annuum) and coconut (Cocos nucifera), producing an authenthic aroma and a classic taste to the dish. After the duration of boiling, the fish is cooked and ready to be served, with the cooked shoots/leaves taken up as a salad together with the fish meat. The preparation process undertaken ultimately softens and crushes the fish's bones making them fragile and easily consumed. 


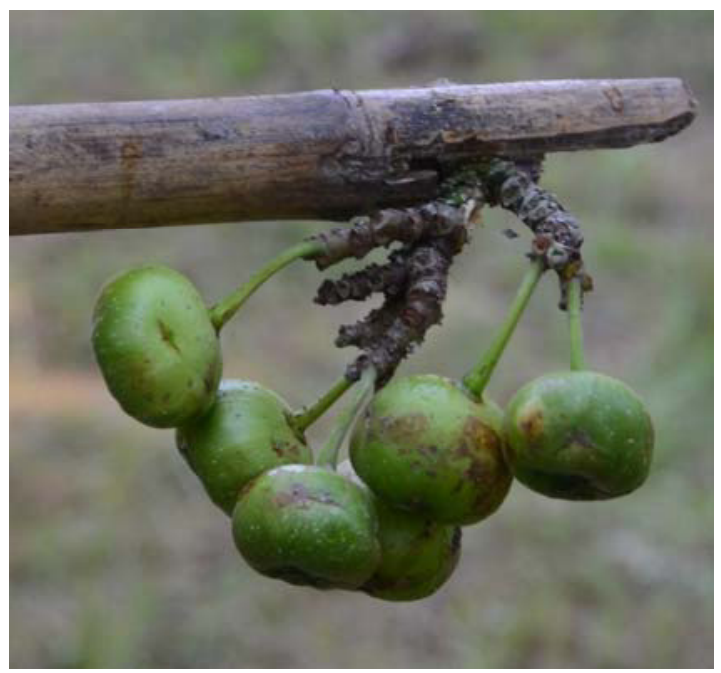

Figure 2. Fruits (young and unripe) of Ficus hispida

Ficus hispida is a woody shrub (10-15m tall) from the Family Moraceae. The small tree bears fruits on its stems. Fruits of Ficus hispida (Picture 2) are also stated as another edible plant part by the community in Lembah Lenggong. The fruits are decocted with charcoal ashes to remove the hispids or the rough bristles and stiff hairs covering the fruit surface. The candied fruits of Ficus hispida are known as 'halwa'.

Knowledge on the use of, especially the leaves of Ficus hispida, is only known and practiced amongst the locals in Lembah Lenggong. This gives Ficus hispida the authentic value of being a traditional food of the specific community because the traditional knowledge is only possessed by them. The uniqueness of the traditional dishes using Ficus hispida is segregated from the present traditional food. Most of the traditional foods that presented today unfortunately have become fusion food, though are still claimed as "traditional food". Ismail et al. [12] stated that the authenticity of traditional food now is hardly apparent due to technologies and modernization. Deliberately, it is affecting the food preferences and eating habits of the current generation towards authentic traditional food. In the long run, the traditional food sadly might lose its authenticity and the heritage products will no longer be preserved for posterity. This loss of authenticity can have even deeper consequences if natural resources are lost or are no longer available.

The introduction of local traditional cuisine to the younger generation is one way to commemorate the old traditions in the preparation process. Major factors influencing the food preferences amongst the tourists include the quality of taste and authenticity of the experience [13]. The local's traditional cuisines play an important role in providing the ideas on the local's image specifically in languages and landscape of a particular region [14].

Food is one of the vital factors that motivate a tourist to travel. Generally, there are four motivational categories involved in the determining process for an individual to travel to a particular region - physical motivators, cultural motivators, interpersonal motivators, and social status and prestige motivators. All these four categories are closely related to local's food preferences [15]. Originality, satisfaction with food attributes and food image are the qualities mostly preferred amongst the international tourists. Previous research by Shahrim and Chua [16] emphasised that the uniqueness of Malaysia food is the utmost value looked up in a travel by international tourists.

Therefore, the revealing study of the authenticity of Ficus hispida as a local traditional product of the community in Lembah Lenggong (World Heritage Site) has a high significance to be established as a cultural tourism product. Unfortunately, the knowledge of utilizing it is solely prevails amongst the elders. The valuable traditional knowledge presented as a product of heritage may perish in time if it is scarcely applied and forgotten by the younger generation. This report depicted that the process of preparing 'Masak Pindang' is only popular amongst the elder generation 
and attained less involvement from the younger generation. Factors affecting the participation of younger generation are the preferences on readymade product on market, fast food, time, the complexity of the process and manifold other reasons.

\section{Conclusion}

Inventorying the importance and resource utilization of plant species by the local communities of Lembah Lenggong was an integral part of this ongoing study. The vast number of plant species present in the region is an integral part of the livelihood of the locals. A wide variety of plants are used through diverse modes of pharmacological and food preparations, in which Ficus hispida attributes a greater interest in terms of its authenticity. Ficus hispida is thus an interesting plant species in Lembah Lenggong, not only for their usefulness but also for its tourism significance. Its restricted distribution to the region of Lembah Lenggong provides a good natural resource and various ecological services.

The uniqueness of the local's traditional dishes especially 'Masak Pindang' ought to be recognized as one of the cultural products in the Lembah Lenggong. The rich knowledge regarding their use of this species in cooking purposes has the potential in elevating it as an eco-tourism or cultural tourism product. The traditional knowledge primarily in culture should be cherished and preserved to be learned, experienced and well accepted by the next generation.

In conclusion, the raising of the awareness towards the importance of biodiversity and the alarming rate at which the natural resources are being exploited from natural habitats has led to the initiation of various conservation actions to mitigate such uncontrolled resource exploitation and its management. This reminder has always been in consideration whenever the studies we undertaken involve the aspects of natural resources, culture, heritage and tourism.

\section{Acknowledgement}

A great appreciation is dedicated to the local community in all villages in the 3 sub-districts in Lembah Lenggong for their patience and willingness to share their traditional knowledge. This work was supported in part by Sustainable Tourism Research Cluster (STRC) USM and Fundamental Research Grant Scheme (FRGS).

\section{References}

1. European Communities, European Research on Traditional Foods, ISBN 92-79-03315-8 (2007)

2. H. Humairah, S.A.K. Muhammad, O. Mohiddin, H. Azimi, Dimensions of Authenticity in Malay Cuisine from Experts' Perspectives. Academic Journal of International Studies, 2, 3, ISSN 22813993 (2013)

3. T. Arunmozhi, A. Panneerselvam, Types of Tourism in India, International Journal of Current Research and Academic Review, 1, 1, 84-88 (2013)

4. J. Bessière, Local Development and Heritage: Traditional Food and Cuisine as Tourist Attractions in Rural Areas. Sociologia Ruralis, 38, 1, 21-34 (1998)

5. OECD, The Impact of Culture on Tourism 5-155 ISBN- 978-92-64-05648-0 (2009)

6. UNESCO Bangkok, Impact: The effects of Tourism on Culture and The Environment in Asia and the Pacific, Tourism and Heritage Site Management Luang Prabang, Lao PDR, 5-124, ISBN 929223-033-6 (2004)

7. G. Richards, Cultural Tourism in Europe, Original published by CABI, Wallingford, UK. C Atlas 2005 (1996)

8. M. Mawere, T.R. Mubaya, The Role of Ecotourism in The Struggles for Environmental Conservation and Development of Host Communities in Developing Economies: The case of 
Mtema Ecotourism centre in South-eastern Zimbabwe, Journal of Research in Peace, Gender and Development. 2, 4, 95-103 (2012)

9. S.L.J. Smith, The Tourism Product. Annals of Tourism Research, 21, 3, 582-595 (1994)

10. NWHO, A Review of Development Assistance and its Potential to Promote Sustainability, Report on Sustainable Tourism and Cultural Heritage, 1-56 (1999)

11. O.C Aworth, The Role of Traditional Food Processing Technologies In National Development: West African Experience, Chapter 3 from Using Food Science and Technology to Improve Nutrition and Promote National Development by Robertson, G.L. \& Lupien, J.R. (Eds) CInternational Union of Food Science \& Technology (2008)

12. N. A. Ismail, Ab. Karim, M. S., M. Othman, N. Abd. Halim, The values of the traditional culinary practices towards the modernization as perceived by the Malay Chefs in Klang Valley, International Food Research Journal, 20, 5, 2857-2864 (2013)

13. H.R. Yurtseven, O. Kaya, Local food in local menus: The case of Gokceada, Tourismos: An International Multidisciplinary Journal of Tourism, 6, 2, 263-275 (2011)

14. T. Oakes, Eating the Food of the Ancestors: Place, Tradition and Tourism in a Chinese Frontier River Town. Eucumene 6, 2, 124-145 (1999)

15. K. Matlovičová, M. Pompura, The Culinary Tourism in Slovakia. Case Study of The Traditional Local Sheep's Milk Products in The Regions of Orava and Liptov, GeoJournal of Tourism and Geosites, 2, 12, 129-144 (2013)

16. M.A.K. Shahrim, B.L. Chua, Malaysia as a Culinary Tourism Destination: International Tourists' Perspective, Journal of Tourism, Hospitality \& Culinary Arts, Chapter 4, 63-78 (2009) 